\title{
UN RECORRIDO BIBLIOGRÁFICO POR LOS CONCEPTOS SUJETO-SOCIEDAD, CUERPO, INDUMENTARIA Y SUS INTERRELACIONES*
}

\section{A BIBLIOGRAPHIC PATH THROUGH SUBJECT-SOCIETY, BODY AND CLOTHING CONCEPTS AND THEIR INTERRELATIONSHIPS}

\author{
María Eugenia VelázQUez**
}

\begin{abstract}
*Trabajo realizado en el marco del proyecto Metáfora y episteme: Hacia una hermenéutica de las instituciones (PICTO 2011 - 0201) de la Agencia Nacional de Promoción Científica y Tecnológica (ANPCyT). Directora del proyecto: Dra. Lidia Raquel Miranda, Miembro de la Carrera del Investigador Científico del Consejo Nacional de Investigaciones Científicas y Técnicas (CONICET) y Profesora Adjunta en la Facultad de Ciencias Humanas de la Universidad Nacional de La Pampa (UNLPam).

**Licenciada en Psicología. Ayudante de Primera en Psicología Institucional en la Cátedra I en la Facultad de Psicología de la Universidad de Buenos Aires (UBA) e investigadora de apoyo en el proyecto Metáfora y episteme: Hacia una hermenéutica de las instituciones (PICTO 2011 - 0201) de la Agencia Nacional de Promoción Científica y Tecnológica (ANPCyT). E-Mail: mevtat@gmail.com Pestalozzi 625 (L6304CII) Santa Rosa, La Pampa. República Argentina.
\end{abstract}

\section{RESUMEN}

Se parte de la hipótesis de que la indumentaria funcionaría como metáfora de la propia personalidad y de los vínculos que establece el sujeto con su entorno y la sociedad en su conjunto.

Se informa un recorrido bibliográfico proponiendo la creación y búsqueda de conceptos ordenadores. La construcción de yuxtaposiciones de conceptualizaciones provenientes de distintas disciplinas que dan cuenta de un fenómeno común, permitiría producir visiones novedosas sobre la temática estudiada. A partir del rastreo bibliográfico realizado se concluye que la indumentaria, en su relación con el cuerpo puede pensarse más que como una metáfora, como una dialéctica. Puede aventurarse que el vestido formaría parte constitutiva de la o las imágenes corporales que se tienen de sí mismo, por lo cual integraría la identidad de los sujetos e intervendría en la regulación de los intercambios sociales que los individuos establecen con otros y con su entorno.
Palabras clave: Institución; Cuerpo; Indumentaria; Cultura; Sociedad; Metáfora; Subjetividad.

\section{ABSTRACT}

The objective of this essay was to perform a bibliographic exploration that engages sources from different social science disciplines, aiming to establish some of the connections that occurs between culture and body image's construction, and between the latter and clothing. Body and clothing are taken as object of study with the purpose of continuing the work already carried on in a previous paper (Velázquez, 2011). Although the preceding investigation takes the hypothesis that the dress would work as a metaphor for the personality and the connections the subject establishes with its immediate environment and society as a starting point, the traditional hypothetico - deductive method was not used. The social sciences, among which are included some of the disciplines that will 
be taken here as a reference, can be considered multi-paradigmatic. They are not regulated by a single theoretical paradigm as Kuhn (1971) praised, but instead they rely on multiple theories or logic-bubbles (de Bono, 1992) that achieve partial statements, or attempts at explanations, reduced to the portion of reality that each of them take as object of study. In this context, the multiple theories that coexist in social sciences overlap explanations, arise conceptual conflicts and let, most certainly, gaps and blind spots in the limits of their conceptions. It is therefore proposed, for the sake of scientific progress out of conflict and creativity, the search and creation of organizing concepts according to Saltalamacchia (1997). The articulation of theories from different disciplines, understood as overlapping metaphors that try to explain the same reality, enables the production of novel insights about the studied subject and the creation of new theories.

Given the bibliographic research done, it can be visualized that subjectivity and society are in fact a network of relationships which effect on actual practice and daily life is structured by imaginary significations (Castoriadis, 1975) that configure the way we act and think. It can be also be stated that body and clothing can become a privileged observable for the study of the workings of this web of interrelationships. Therefore, studying the field in which clothing, inextricably related to the body, intervenes, and the ways in which it does, involves analyzing the discourses, practices and institutions that shape the representations of body, identity and society.

Clothing, in its relation to the body, can be conceived as dialectic rather than as a metaphor. If, in opposition to substantialism (Carpio, 2003), things cannot be considered in themselves but only in terms of their relations, it is possible to conceive the biological body as the thesis and clothing as the anti-thesis, the synthesis of which would be body image or images. In this line of thought, it can be ventured that clothing may be a constituent part of the body image that we form of ourselves, reason because it also would integrate the identity of subjects and intervene in the regulation of social exchanges that individuals establish with others and with their environment.

The study of the specific ways in which clothing is involved in the relationships that individuals establish with their surroundings and society can be enriched from different disciplinary perspectives and under the scrutiny of various methods of analysis. All these lines of analysis will be stimulating and appropriate for the planned study. In this respect, this assay attempts to register a particular bibliographic tour, among many possible others, that is concerned with the issue under study and report on the significant contributions that may be useful for investigations of this nature. Undoubtedly, this task has an initial character and will achieve its full significance once the contributions collected are tested in the fieldwork.

Key words: Institution; Body; Clothing; Culture; Society; Metaphor; Subjectivity.

\section{INTRODUCCIÓN}

En este ensayo se realiza un recorrido bibliográfico, tomando aportes de distintas disciplinas, para establecer algunas relaciones que se dan entre la cultura y la construcción de la imagen corporal, y entre la imagen corporal y la indumentaria como punto de partida para una indagación que necesariamente deberá completarse en posteriores instancias investigativas. Se toma como objeto de estudio privilegiado el cuerpo en términos generales y su relación con la indumentaria, para dar continuidad a los avances que se venían realizando en investigaciones precedentes (Velázquez, 2011). Si bien este estudio parte de la hipótesis de que la indumentaria funcionaría como metáfora de la propia personalidad y de los vínculos que establece el sujeto con su entorno próximo y la sociedad en su conjunto, no se utiliza el método hipotético deductivo tradicional.

Sería imposible iniciar cualquier investigación sin conjeturas, ya que supondría la concepción del investigador como una tabula rasa o la posibilidad de partir desde la nada. Es por esta razón que aquí se incluye explícitamente la hipótesis de origen, procurando evitar las estructuraciones técnicas que conduzcan forzosamente a su verificación. 
Alejándose del modelo positivista y experimental, se intenta tener una postura dispuesta al hallazgo (Mancovsky, 2011). Es decir, mantener una tensión constante entre un saber que es buscado y un no-saber vinculado a la capacidad de asombro y sorpresa de lo que se puede llegar a encontrar.

El estudio que se informa está enmarcado dentro de lo que en Argentina se conoce como Psicología Institucional, postura ideológicometodológica creada y desarrollada por Ulloa (1995) desde la década del 70. En otras áreas disciplinares de nuestro país pueden encontrarse posturas similares con otra denominación, por ejemplo enfoque clínico de las Ciencias Sociales (Mancovsky, 2011). En otros países, donde la Psicología Institucional no existe, como en México, el mismo quehacer se enmarca dentro de la Psicología Social (Salazar Villava, 2004). Pero sea cual fuere el nombre elegido, se caracteriza por dos ejes fundamentales: un intento permanente de romper con la antinomia individuo-sociedad que trasciende las disciplinas y, por lo tanto, se ve apoyado en la utilización de los conceptos provenientes de distintos marcos teóricos, que colaboren en la comprensión y análisis de la situación estudiada; y la relativización de la pretensión de objetividad en el abordaje, análisis e interpretación del objeto, a partir del permanente y continuo trabajo sobre la propia subjetividad mediante el análisis de la implicación (Lourau, 1991).

Las ciencias sociales, en las que se inscriben algunas de las disciplinas que se tomarán como referencia, pueden considerarse multiparadigmáticas. No se rigen por un único paradigma teórico tal como lo planteara Kuhn (1971), sino por múltiples teorías o burbujas lógicas (de Bono, 1992) que logran afirmaciones parciales, o intentos de explicaciones, reducidas a la porción de realidad que toman como objeto de estudio. En este marco, las múltiples teorías que conviven en las ciencias sociales superponen explicaciones, plantean conflictos conceptuales y dejan, sin lugar a dudas, huecos y puntos ciegos en los límites de sus concepciones. Se propone entonces, en aras del avance científico a partir del conflicto y la creatividad, la creación y búsqueda de conceptos ordenadores (Saltalamacchia, 1997), la construcción de yuxtaposiciones, más o menos ordenadas, de conceptualizaciones provenientes de distintas disciplinas que dan cuenta de un fenómeno común. La articulación de teorías provenientes de distintas disciplinas, entendidas como metáforas superpuestas que intentan dar cuenta de una misma realidad, permite producir visiones novedosas sobre la temática estudiada y crear nuevas teorías. Así, los esquemas conformados por relaciones conceptuales se construirán a través de procesos helicoidales de abstracción e inducción, a partir de la comprensión (siempre inacabada) del objeto y los fenómenos sociales que lo fundamentan. A su vez se propone un análisis recursivo sostenido en una interacción entre observación, análisis e interpretación (Vieytes, 2004).

La relevancia del tema abordado se fundamenta en un intento de rebasar el estudio histórico de las instituciones para analizar su formulación lingüístico-discursiva metafórica en un corpus textual amplio correspondiente a distintas disciplinas (Sociología, Antropología, Psicología, Literatura y Filosofía). Estos discursos configurarían una base simbólica común que es la metáfora.

Se parte de una concepción del vínculo social tal como la plantea Castoriadis (1975). Se entiende a la institución social como una urdimbre de instituciones parciales. Estas instituciones parciales, entendidas como mitos, ritos, modos de hacer y de comprender el mundo, valores, lenguaje, normas, etc. vinculan tanto a los individuos como a las entidades colectivas. Funcionan como un magma de significaciones imaginarias sociales que orientan y dirigen la vida social dándole a su vez unidad. Y es en el estudio de estas instituciones, desde distintas perspectivas epistemológicas, que se encuentra un centro problemático común que motiva nuestra investigación: la metáfora.

Las significaciones imaginarias sociales en sí mismas ya constituyen una metáfora. Son imaginarias en tanto que no corresponden a ningún elemento real o racional, sino que son dadas por creación (Castoriadis, 1975), de forma arbitraria, y sociales ya que se encuentran 
instituidas y compartidas por un ente colectivo anónimo. Estas dos características hacen que las significaciones imaginarias sociales estén en continuo movimiento y transformación, desplazando continuamente su significación a nuevas significaciones. Y sin embargo, mantienen una unidad o eidos que permite identificarla como la misma sociedad.

En esta línea, se entiende la metáfora tal como la conciben Lakoff y Johnson (2005). En el día a día se piensa y se actúa, más o menos automáticamente, asentándose en ciertas pautas conceptuales (significaciones imaginarias sociales - Castoriadis, 1975). Una forma de acceder a dichas pautas es a través del análisis del lenguaje y la comunicación cotidiana. A partir de evidencias lingüísticas, los autores descubren que gran parte del sistema conceptual ordinario se estructura en base a metáforas influyendo directamente en la organización de la actividad diaria. La metáfora es así concebida no como un rasgo exclusivo del lenguaje, sino como parte integral del sistema conceptual ordinario que estructura la forma de pensar y actuar de las personas.

\section{EL CUERPO EN RELACIÓN A LO SOCIAL}

El tratamiento del cuerpo humano como tema de investigación favorece particularmente el análisis social, cultural y psicológico ya que se vincula con el principio de la identidad de las personas. Freud señala que en la génesis del Yo juegan un papel fundamental las percepciones, internas y externas, que se obtienen a partir del cuerpo. Más aún, dice que el Yo es en sí mismo corpóreo (Freud, 1923). Pero es un error creer que el cuerpo viene dado naturalmente. Muy por el contrario, se trata de una construcción social y cultural, lo que se verifica en estudios antropológicos (Le Breton, 1995), psicológicos (Nasio, 2008) y sociológicos (Heidt, 2004).

Las ciencias sociales, humanísticas y de la educación, en general, se preocupan por investigar el modo en que cada cultura modela la personalidad de los individuos, consciente $\mathrm{o}$ inconscientemente, mediante sus instituciones y los modelos que le propone, así como las maneras en que cada sujeto sabe servirse de su cuerpo para modelizar, a su vez, los espacios simbólicos y pragmáticos de las relaciones con los demás. Por otro lado, la historia de la literatura revela la importancia que el cuerpo ha tenido siempre como referencia para describir el mundo (Miranda, 2004). En torno al cuerpo y en relación con él, el espacio se organiza como un sistema y la dimensión topológica se manifiesta con frecuencia en alusión a la ubicación de las partes del cuerpo: el pie de la montaña o el camino de cintura. A su vez el cuerpo también ha sido utilizado para metaforizar el orden y el desorden social (Heidt, 2004). Se habla así de la cabeza del estado, el ojo de la ley o bien puede declamarse acerca de los enemigos de un sistema que son la enfermedad que ataca al cuerpo social.

La historia del cuerpo humano, tal como señala Porter (1996), ha tomado vigor en época reciente y ha dado lugar a relevantes trabajos históricos que ahondan en las distintas concepciones del cuerpo, en su carácter simbólico e ideológico y en su significación como modelo espacio-temporal de la existencia. Las representaciones de género y etnicidad en la construcción de la sociedad no se hallan ausentes entre las preocupaciones actuales del estudio histórico. Según Foucault (1989), los historiadores que han estudiado el cuerpo en el campo de la Demografía o de la patología histórica lo han considerado, por un lado, un lugar de necesidades y de apetitos y, por otro, un centro de transformaciones físiológicas y metabólicas. Así han podido demostrar que los procesos históricos están implicados también en la base biológica de la existencia y que la historia de las sociedades y la de los acontecimientos biológicos se hallan en permanente y estrecha relación.

Los sujetos son artífices y actores sociales de su propio mundo. La forma en que se percibe la realidad se presenta como natural y permanente, sin embargo es una construcción histórico-social de la cual los individuos son productos y productores. Los mitos, ritos, ideologías, valores, procedimientos y méto- 
dos, entre otros múltiples elementos, englobados todos ellos en la noción de significaciones imaginarias sociales (Castoriadis, 1975), son el resultado de una labor colectiva en un tiempo y espacio determinados, que asegura su cohesión y permanencia en el tiempo. Un claro ejemplo de cómo la influencia social modeliza los cuerpos es demostrado en profundidad por Elias (1987), que a partir de un estudio sistemático de lo que él llama el proceso de civilización y el acortesamiento de los guerreros, establece una relación directa entre los cambios sociales a gran escala y los cambios subjetivos que se evidencian en las modificaciones de los usos del cuerpo que acontecen paulatinamente entre los Siglos XI y XVIII. Elias puede ser considerado un precursor en una Sociología corporo-emocional (Vergara, 2007) con dos aportes fundamentales. En primera instancia, enlazado al campo de la Psicología, el autor plantea durante este período sociohistórico la diferenciación y estabilización del Super Yo a partir de un progresivo autocontrol y la interiorización de las coacciones sociales (Elias, 1987). Y por otro lado, plantea una ruptura con las teorías psicológicas clásicas en tanto que estas se apoyan en una dicotomía individuo/sociedad. El autor acentúa la necesidad de pensar los permanentes cambios sociales en tanto procesos que configuran una red de interdependencia en el entramado humano. Y para lograrlo propone la búsqueda de nuevos medios conceptuales y lingüísticos:

"El concepto de «sociedad» mismo tiene este carácter de objeto aislado en situación de reposo, igual que el de «naturaleza». Lo mismo sucede con el concepto de «individuo». En consecuencia nos vemos una y otra vez obligados a utilizar formulaciones absurdas como, por ejemplo, «individuo y sociedad», que da a entender que «individuo»y «sociedad» son cosas distintas, como una mesa y una silla o una olla y una marmita" (Elias, 1982, p. 66).

En el campo de la comunicación no verbal, la relevancia de las conductas corporales, asociadas con el entorno personal, tanto en el tratamiento de trastornos psicológicos y de aprendizaje como en la formación de rasgos culturales, ha sido demostrada por numerosos estudios impulsados en el último tramo del Siglo XX en el seno de diversas disciplinas tales como la Psicología, la Psiquiatría, la Pedagogía y la Antropología Cultural.

En relación a la sociología del vestir Entwistle (2002), en el marco de una crítica general a las conceptualizaciones teóricas generadas hasta el momento por diferentes disciplinas, propone una visión sociológica de la moda-vestir como práctica corporal contextuada.

\section{EL CUERPO Y LA INDUMENTARIA EN RELACIÓN A LA CONSTITUCIÓN SUBJETIVA}

Los estudios psicológicos no están ausentes en el panorama contemporáneo sobre las indagaciones de la relación entre individuo, cuerpo y sociedad. Los padres, primeros objetos de amor del niño, son internalizados poco a poco por el recién nacido, conformando una parte íntima de su personalidad. La familia, como primer espacio de socialización de los sujetos, transmite a su vez los imaginarios sociales de un tiempo y un lugar determinados, concebidos éstos como formas de hacer, mitos, ritos, reglas, costumbres, significaciones $\mathrm{y}$, en general, todo aquello que es pasible de ser pensado en una sociedad y que permite que las personas se manejen con su realidad cotidiana con una obviedad indiscutible. La imagen o las imágenes que los individuos tienen de su propio cuerpo no escapa/n a estas vinculaciones. Si bien la imagen de base ${ }^{1}$, que es inconsciente, posee cierta dimensión estática, la imagen funcio-

\footnotetext{
Ligada íntimamente al narcisismo primordial, la imagen de base "nos da la triple sensación de permanecer estables en el espacio, de seguir siendo el mismo en el tiempo y de conservarnos consistentes frente a la alteridad de los seres y las cosas" (Nasio, 2008, p. 151).
} 
nal $^{2}$ y la imagen erógena ${ }^{3}$ (Dolto, 1979) se refieren a la huella dejada por el inconsciente infantil, de lo que siente un cuerpo en la relación con un otro deseado y deseante (Nasio, 2008).

En cuanto a los antecedentes puntuales, desde distintas disciplinas, con respecto a la perspectiva de la relación cuerpo-constitución subjetiva se han encontrado desarrollos teóricos. Burns (2002) acuña el término sartorial bodies para referirse a

"... bodies forged from what we might call a sartorial corporeality, courtly bodies generated by clothes that extend the flesh of literary protagonists symbolically and ideologically"4 (p. 13).

En relación con la problemática cuerpoatuendo, Hunn y Kaiser (2001) analizan los cambios revolucionarios en la vestimenta infantil acaecidos entre 1896 y 1962 y lo refieren a la construcción binaria del género en el sistema moderno. Asimismo Kaiser (2004) trabaja la relación entre la producción y reproducción de la categoría sujeto femenino de consumo blanco, heterosexual y de clase media / alta, en la nueva población de consumo llamada tweens en EEUU y que en la Argentina podría definirse como pre-adolescentes de entre 7 y 12 años. Por su parte, Velázquez (2011) desarrolla algunas de las significaciones culturales sobre el cuerpo que circulan en la actualidad y tienen efectos concretos en la constitución subjetiva de los individuos contemporáneos.

2 "Imagen esténica -de fuerza- que apunta a la satisfacción del deseo del sujeto" (Dolto, 1979, p. 5).

3 "Es el lugar donde se concentran el placer o el displacer erótico en la relación con el otro" (Dolto, 1979, p. 57).

4 “[...] cuerpos forjados por lo que podríamos llamar una corporeidad relativa a la sastrería, cuerpos corteses generados por una vestimenta que es una extensión, simbólica e ideológica, de la carne de los protagonistas de la literatura" (traducción de la autora).
En cuanto a antecedentes puntuales desarrollados en nuestro país no se pueden dejar de mencionar los tratamientos en Sociología de la Moda de Saulquin (1990, 2004, 2010), llevados adelante tanto individualmente como con su grupo de investigaciones del vestir del Instituto de Sociología de la Moda (Buenos Aires, Argentina). Asimismo son relevantes los trabajos de Zambrini (2008, 2010, 2011a, 2011b) que analizan la relación entre indumentaria, cuerpo e identidades de género a partir de la performance travesti en el país.

En lo que se refiere a los estudios del cuerpo en relación con el vestido en la dimensión subjetiva, Flügel (1964) propone que la vestimenta extiende el yo corporal. Al ponerse el cuerpo en contacto con un objeto externo, por ejemplo un vestido, una herramienta o un bastón, se tiene la sensación subjetiva de que el propio cuerpo se extiende a los extremos de este objeto extraño. En la dimensión social es a través de la vestimenta y la apariencia general o fachada personal (Goffman, 1993) que se realizan los primeros juicios de valor sobre las personas, ya que es lo primero que se puede apreciar a la distancia y lo que indica, a grandes rasgos, sexo, origen social y posibles formas de interacción a establecer con el sujeto (Flügel, 1964).

Entwistle (2002) plantea que los desarrollos científicos en Psicología, Sociología, estudios culturales y otras disciplinas tienden a separar el estudio de la vestimenta del cuerpo, $\mathrm{y}$ al hacerlo se fragmenta parte del objeto que se pretende estudiar.

Ya Freud (1955) concebía el desarrollo de la psique humana asociado a la necesaria influencia de la sociedad en la que habitan los sujetos, perspectiva que sin embargo, el psicoanálisis hoy tiende a dejar de lado en aras de una óptica más individualista. Nasio (2008) analiza los conceptos de imagen corporal de dos exponentes fundamentales del psicoanálisis: Dolto y Lacan. Mientras que el primero concibe una teoría a partir de las sensaciones físicas y las imágenes no visuales, el segundo trabaja con la imagen especular y la fascinación que ella produce en el niño que aún no tiene total control sobre su 
cuerpo. Una tercera perspectiva es incorporada por Nasio a las reflexiones sobre el cuerpo al entender el proceso de constitución de la instancia yoica como el resultado de la fusión entre ambas imágenes, la del cuerpo que se ve y la del cuerpo que se experimenta. Flügel (1964) también retoma la teoría freudiana y plantea, a partir de la concepción de que los sujetos son constitucionalmente bisexuales, que la ropa juega un papel fundamental en el proceso de identificación con los géneros masculino o femenino.

\section{CONCLUSIONES Y DISCUSIÓN}

A partir del estudio bibliográfico realizado se puede visualizar que lo subjetivo y lo social son una red de interrelaciones cuyo efecto en la práctica concreta y la vida cotidiana se estructura a partir de significaciones imaginarias sociales que configuran nuestros modos de hacer y pensar. Además es posible afirmar que el cuerpo y la indumentaria se constituyen en un observable privilegiado para el estudio del funcionamiento de esta red de interrelaciones. Por lo tanto, estudiar el campo en que el vestido, indisolublemente asociado al cuerpo, interviene, y los modos en que lo hace, supone analizar los discursos, las prácticas y las instituciones que modelan las representaciones del cuerpo, la identidad y la sociedad.

En esta línea de pensamiento podría plantearse, como en la hipótesis inicial, que la vestimenta funcionaría como metáfora de la propia personalidad y del tipo de relación que se quiere establecer con el mundo circundante. Darían cuenta de ello los movimientos sociales que se plantean en desacuerdo con la moral dominante y lo manifiestan, entre otras formas, a través de su indumentaria: punks, hippies, skin-heads. Los góticos y darks expresan una visión melancólica y pesimista de la vida a través del uso de vestimentas de color negro, socialmente asociado al luto. Un ejemplo más claro al que puede recurrirse es el de las personas travestis, femeninas o masculinas. Contrariados en lo biológico, expresan al mundo la forma en que se autoperciben y desean que las personas los traten de acuerdo con la identidad de género exteriorizada en su indumentaria.

Desde esta perspectiva, el vestido, en tanto dispositivo del cuerpo, se constituiría en un valor, en una representación que delimitaría a cada uno frente a los demás, a partir de la cual, en todo momento, el sujeto simbolizaría la calidad de los contactos que establece con el mundo. Sin embargo, la elección y el uso de la vestimenta corporal resulta ser un factor fundamental en el intercambio de encuentros y relaciones en la esfera pública porque se transforman en un habitus (Bourdieu, 1980) para cada grupo social, lo que determina un conjunto de normas de conducta que pautan la relación de cada individuo con su cuerpo y con los cuerpos ajenos. El habitus es entendido por Bourdieu como un conjunto de disposiciones estructuradas y estructurantes que naturalizan nuestras formas de pensamiento, percepción y acción. Así, el habitus sería lo social incorporado en los cuerpos, que a su vez legitima y naturaliza los esquemas prácticos de visión dominantes en los dominados. Bourdieu indica la función solidaria que tiene la indumentaria femenina con respecto a la dominación masculina y el pensamiento androcéntrico en tanto que colabora en el empequeñecimiento de la mujer limitando sus movimientos.

"Porque condiciona de diferentes maneras los movimientos, como los tacones altos o el bolso que ocupa constantemente las manos, y sobre todo la falda, que impide o dificulta cualquier tipo de actividades (la carrera, diferentes maneras de sentarse, etc.), o porque sólo las permita a costa de constantes precauciones, como en el caso de las jóvenes que estiran constantemente su falda demasiado corta, se esfuerzan en cubrir con su antebrazo un escote demasiado amplio o tienen que realizar auténticas acrobacias para recoger algo sin abrir las piernas. Estas maneras de mantener el cuerpo, profundamente asociadas a la actitud moral y al pudor que deben mantener las mujeres, siguen imponiéndose, como a pesar suyo, incluso cuando dejan de ser im- 
puestas por el atuendo (pensemos en los pasitos rápidos de algunas muchachas con pantalones y zapatos planos)" (Bourdieu, 2010, pp. 41-42).

A este tipo de conceptos límite, que articulan los espacios psíquicos entre bordes heterogéneos, Kaës y colaboradores (1989) los llaman formaciones intermediarias. El autor ubica a la institución (Castoriadis, 1975) como una cuarta herida narcisista infligida a la humanidad, que da cuenta de que el inconsciente no es una propiedad personal sino que se apuntala en lo social.

"La posición tópica y funcional de este espacio psíquico institucional interno-externo es comparable al de la pulsión. Se trata de dos conceptos - límites que articulan, por vía del apuntalamiento, el espacio psíquico a sus dos bordes heterogéneos: el borde biológico, que la experiencia corporal actualiza, y el borde social, actualizado por la experiencia institucional" (Kaës et al., 1989, p. 17).

De esta forma el habitus de Bourdieu y la indumentaria se podrían pensar como una, entre múltiples formaciones intermediarias.

La indumentaria, en relación con el cuerpo puede concebirse, más que como una metáfora, como una dialéctica. Si en oposición al sustancialismo (Carpio, 2003), las cosas no pueden considerarse en sí mismas sino exclusivamente en función de sus relaciones, puede pensarse el cuerpo biológico como la tesis y la indumentaria como la antitesis, dando como resultado en su síntesis la imagen o las imágenes corporales. Cuando se compra ropa para un allegado, no solo se piensa en su talle o su funcionalidad, también se contempla su gusto, estilo y personalidad. Se identifica la indumentaria con el sujeto que la usará y hasta puede llegar a pensarse 'esta prenda es justo para Fulanito de Tal'. Cuando se elige un atuendo para uso personal queremos que nos quede cómodo. Pero esta comodidad no tiene que ver exclusivamente con la confección o las características físicas de la prenda. Lo que se busca es que refleje la percepción que tenemos de nosotros mismos. Así una persona puede sentirse más cómoda con tacos y minifalda que con un jogging. Y a su vez, el modo que tenemos de percibirnos a nosotros mismos está condicionado socialmente. De esta forma, puede aventurarse que el vestido formaría parte constitutiva de la o las imágenes corporales que se tienen de uno mismo, por lo cual integraría la identidad de los sujetos e intervendría en la regulación de los intercambios sociales que los individuos establecen con otros y con su entorno.

Saltalamacchia (1997) advierte acerca de los límites del modelo heurístico por él propuesto y utilizado, centrándose específicamente en dos cuestiones. Por un lado, el recorte conceptual, aunque desarticulado de las teorías madres, tiende a convertir lo dado en dato. Es decir, a interpretar el recorte en función de la teoría. Con este modo de proceder, lo que se intenta es relativizar las certezas y los límites del recorte realizado, sin negarlos. Por el otro, a pesar de que el recorte puede provenir de corpus conceptuales heterogéneos, la lectura que se realiza de ellos, en tanto que es realizada por un sujeto investigador, está guiada inevitablemente ideológica y/o teóricamente.

El investigador es necesariamente parte de una sociedad, y por lo tanto sus modos de ver, entender y conceptualizar la realidad se encuentran más o menos condicionados por esa pertenencia. Por eso es fundamental incluirlo dentro del campo de análisis (Lourau, 1991). El estudio de los modos concretos en que la vestimenta interviene en el tipo de relaciones que los individuos establecen con su entorno y la sociedad en su conjunto puede ser ampliado desde distintas perspectivas disciplinarias y bajo la lupa de diversos métodos de análisis. Todas estas líneas de análisis resultarán estimulantes y apropiadas para el estudio que se desea realizar. En tal sentido en el estudio que se informa se ha procurado registrar un particular recorrido bibliográfico, entre otros múltiples posibles, que se ocupa de la problemática y dar cuenta de los aportes significativos que pueden ser de utilidad para indagaciones de esta naturaleza. Sin duda, esta tarea tiene carácter inicial y cobrará sen- 
tido una vez que se continúe con la salida al campo y se pongan a prueba los aportes recogidos.

\section{REFERENCIAS BIBLIOGRÁFICAS}

Bourdieu, P. (1980). Questions de sociologie [Questions of Sociology]. Paris: De Minuit.

Bourdieu, P. (2010). La dominación masculina y otros ensayos [Male domination and other essays]. Buenos Aires: Anagrama.

Burns, J.E. (2002). Courtly love undressed. Reading through clothes in medieval French culture. Philadelphia, Pennsylvania: University of Pennsylvania Press.

Carpio, A. (2003). Principios de filosofía. Una introducción a su problemática [Principles of Philosophy. An introduction to problems]. Buenos Aires: Glauco.

Castoriadis, C. (1975). La institución imaginaria de la sociedad [The imaginary institution of society]. Barcelona: Tusquets Editores.

de Bono, E. (1992). El pensamiento lateral: $M a-$ nual de creatividad [Lateral thinking: Creativity manual]. México: Paidós.

Dolto, F. (1979). La imagen inconsciente del cuerpo [The unconscious body image]. Buenos Aires: Paidós.

Elias, N. (1982). Sociología fundamental [Essential Sociology]. Barcelona: Gedisa.

Elias, N. (1987). El proceso de la civilización. Investigaciones sociogenéticas y psicogenéticas [The civilizing process: Sociogenetic and psychogenetic investigations]. Madrid: Fondo de Cultura Económica.

Entwistle, J. (2002). El cuerpo y la moda. Una visión sociológica [The fashioned body: A sociological view]. Barcelona: Paidós.

Foucault, M. (1989). Vigilar y castigar. Nacimiento de la prisión [Discipline and punish: Birth of the prison]. Buenos Aires: Siglo XXI.
Flügel, J.C. (1964). Psicología del vestido [The Psychology of clothes]. Buenos Aires: Paidós. Freud, S. (1955). Psicología de las masas y análisis del yo. En J.L. Etcheverry (Trad.), Obras completas [Complete works] (Vol. 18). Buenos Aires: Amorrortu. (Trabajo original publicado, 1921).

Freud, S. (1979). El yo y el ello. En J.L. Etcheverry (Trad.), Obras completas [Complete works] (Vol. 19). Buenos Aires \& Madrid: Amorrortu. (Trabajo original publicado, 1923).

Garfinkel, H. (1967). Studies in ethnomethodology. Englewood Cliffs, NJ: Prentice-Hall.

Goffman, E. (1993). La presentación de la persona en la vida cotidiana [The presentation of self in everyday life]. Buenos Aires: Amorrortu.

Guber, R. (2001). La etnografia, método, campo y reflexividad [Ethnography, method, field, and reflexivity]. Buenos Aires: Norma.

Heidt, E.U. (2004), Cuerpo y cultura: La construcción social del cuerpo humano. En D. Perez (Ed.), La certeza vulnerable. Cuerpo y fotografía en el Siglo XXI [The vulnerable certainty. Body and photography in the XXI Century], (pp. 46-64). Barcelona: Gustavo Gili. Hunn, K. \& Kaiser, S. (2001). The emergence of modern infantwear, 1896-1962: Traditional white dresses succumb to fashion's gender obsession. Recuperado el 2 de agosto de 2010 de http://ctr.sagepub.com/ontent/19/3/103.ab stract. http://dx.doi.org/10.1177/0887302X0 101900302

Kaës, R., Bleger, J., Enriquez, E., Fornari, F., Fustier, P., Roussillon, R. \& Vida, J.P. (1989). La institución y las instituciones. Estudios psicoanalíticos [The institution and institutions. Psychoanalytic studies]. Buenos Aires: Paidós.

Kaiser, S. (2004). Betwixt and be tween. Age ambiguity and the sexualization of the female consuming subject. Recuperado el 2 de agosto de 2010 de http://joc.sagepub.com/content/4/ 2/203.abstract 
Khun, T. (1971). La estructura de las revoluciones cientificas [The structure of scientific revolutions]. México: Fondo de Cultura Económica.

Lakoff, G. \& Johnson, M. (2005). Metáforas de la vida cotidiana [Metaphors we live by]. Madrid: Cátedra.

Le Breton, D. (1995). Antropología del cuerpo y la modernidad [Anthropology of the body and modernity]. Buenos Aires: Nueva Visión.

Lourau, R. (1991). El análisis institucional [Institutional analysis]. Buenos Aires: Amorrortu.

Maffesoli, M. (2004). El tiempo de las tribus. El ocaso del individualismo en las sociedades pos modernas [The time of the tribes: Decline of individualism in mass society]. México, DF: Siglo XXI.

Mancovsky, V. (2011). El enfoque clínico en ciencias sociales: La sutil diferencia entre la búsqueda y el hallazgo [The clinical approach in the social sciences: The subtle difference between searching and finding]. Trabajo presentado en el VIII Congreso Internacional de Psicosociología y Sociología Clínica: Transformaciones Sociales y Desafíos del Sujeto. Montevideo, Uruguay.

Miranda, L.R. (2004). Representación y funcionalidad del cuerpo humano en la literatura espanola medieval [Representation and functionality of the human body in medieval Spanish literature]. Santa Rosa: Instituto de Estudios Clásicos (formato $\mathrm{CD}$ ).

Nasio, J.D. (2008). Mi cuerpo y sus imágenes [My body and its images]. Buenos Aires: Paidós.

Porter, R. (1996). Historia del cuerpo. En P. Burke (Ed.), Formas de hacer historia [Ways to make history] (pp. 255-286). Madrid: Alianza.

Salazar Villava, C.M. (2004). Dispositivos: Máquinas de visibilidad [Devices: Visibility machines]. Anuario de Investigación 2003, 291300. Departamento de Educación y Comunicación de la Universidad Autónoma de México.

Saltalamacchia, H. (1997). Los datos y su creación [The data and its creation]. Puerto Rico: Kryteria.
Saulquin, S. (1990). La moda en la Argentina [Fashion in Argentina]. Buenos Aires: Emecé. Saulquin, S. (2004). Jeans, la vigencia de un mito [Jeans, the validity of a myth]. Buenos Aires: Nobuko.

Saulquin, S. (2010). La muerte de la moda, el día después [The death of fashion, the day after]. Buenos Aires: Paidós.

Sorlin, P. (2004). El "siglo" de la imagen analógica: Los hijos de Nadar [The "Century" of the analog image: Nadar's children]. Buenos Aires: La Marca.

Souza Minayo, M. (2004). Investigación social, método y creatividad [Social research method and creativity]. Buenos Aires: Lugar.

Ulloa, F. (1995). La novela clínica psicoanalítica. Historial de una práctica [The clinical psychoanalytic novel. Record of a practice]. Buenos Aires: Paidós.

Velázquez, M.E. (2011). Cuerpo e imagen. Acerca de la construcción de imaginarios sociales sobre cuerpo, derechos e infancia [Body and image. About body, rights and childhood social imaginary construction]. Anuario de Investigaciones, 28(2), 447-454. Facultad de Psicología de la Universidad de Buenos Aires.

Vergara, G. (2007). Cuerpo y sociedad más allá de las dicotomías. Una lectura de Norbert Elías desde la Sociología de los cuerpos y las emociones [Body and society beyond the dichotomies. A reading of Norbert Elias from the Sociology of bodies and emotions]. Recuperado el 24 de noviembre de 2013 de http:// www.accioncolectiva.com.ar/sitio/documentos /gvergara2007b.pdf

Vieytes R. (2004). Metodología de la investigación en organizaciones, mercado y sociedad. Epistemología y técnica [Research methodology in organizations, markets and society. Epistemology and technical]. Buenos Aires: De las Ciencias.

Zambrini, L. (2008). Cuerpos, indumentarias y expresiones de género: El caso de las travestis de la Ciudad de Buenos Aires. En M. Pecheny, C. 
Figari \& D. Jones (Comps.), Todo sexo es político. Estudios sobre sexualidades en Argentina [All sex is political. Sexualities studies in Argentina], (pp. 123-146). Buenos Aires: del Zorzal.

Zambrini, L. (2011a). Modos de vestir e identidades de género: Reflexiones sobre las marcas culturales en el cuerpo [Modes of dress and gender identities: Reflections on cultural marks on the body]. Nomadias, O(11), 130-149. http:/ /dx.doi.org/10.5354/0719-0905.2010.15158

Zambrini, L. (2011b). La feminización de los cuerpos a través de la indumentaria [The feminization of bodies through clothing]. Boletin on line Ciudadanias $x$ Activismo Cultural y Derechos Humanos, 14, Universidad Peruana Cayetano Heredia, Lima, Perú. Recuperado el 12 de agosto de 2012 de http://www.ciudadani asx.org/?la-feminizacion-de-lo s-cuerpos-a

Facultad de Ciencias Humanas Universidad Nacional de La Pampa (UNLPam) República Argentina

Fecha de recepción: 29 de julio de 2013 Fecha de aceptación: 7 de mayo de 2014 
